\title{
Coronary Angioplasty of the Circumflex Artery with anomalous Left Coronary Artery and origin from the Right Sinus of Valsalva
}

\section{"A Case Report"}

Rodrigo A. Martin*, Ricardo Marcelo Cetera, Amalia Descalzo, Sergio Zolorza, General Hospital Presidente Perón. Avellaneda. Interventional Cardiology.

*Corresponding Author: Rodrigo A. Martin, General Hospital Presidente Perón. Avellaneda. Interventional Cardiology.

Received Date: August 03, 2021; Accepted Date: Augusł 30, 2021; Published Date: September 03,2021

Citation: Rodrigo A. Martin, Ricardo Marcelo Cetera, Amalia Descalzo, Sergio Zolorza (2021) Coronary Angioplasty of the Circumflex Artery with anomalous Left Coronary Artery and origin from the Right Sinus of Valsalva "A Case Report". J. Clinical Cardiology and Cardiovascular Interventions, 4(14); DOI:10.31579/2641-0419/207

Copyright: () 2021 Rodrigo A. Martin, This is an open-access article distributed under the terms of the Creative Commons Attribution License, which permits unrestricted use, distribution, and reproduction in any medium, provided the original author and source are credited.
Abstract
We report a patient in the sixth decade of life with a benign anomalous course and a history of atherosclerotic disease in the right coronary artery with the presence of ischemia. We present a clinical case of infrequent finding of abnormal left coronary artery and obstructive atherosclerotic lesion in the circumflex artery. The authors decided to perform coronary angioplasty on the lesion found. Because it is an infrequent condition, we conducted a literature search in which we focused on the statistical findings, the clinical presentation and detailed the treatment of the patient by means of coronary angioplasty. Despite the difficulty of the case, success was achieved.
Keywords: coronary artery; cardiac catheterization; anomalous couse; atherosclerotic disease; coronary angioplasty

\section{Introduction}

The coronary arteries originate from the right and left sinuses of Valsalva. There are causes that can alter their normal origin, course or anatomical arrangement and, although such malformations are rare, they carry a significant risk of arrhythmias, angina, infarction and sudden death, a risk that is higher during childhood and adolescence. The origin of the left coronary artery from the right sinus of Valsalva corresponds to a very infrequent coronary anomaly, with an incidence between 0.2 and $1.2 \%$. It does not usually produce clinical repercussions and its diagnosis is usually an occasional finding. However, it can be associated with myocardial ischemia and even sudden death, especially in young patients during exercise. In case of coronary atherosclerotic disease, it does not usually develop over an anomalous coronary pathway. We present the case of a patient in whom obstructive disease of the circumflex artery was found with origin of the left coronary trunk at the level of the right coronary sinus in which coronary angioplasty with stenting was performed.

\section{Case Report}

A 66-year-old male patient with positive cardiovascular risk factors for hypertension, smoking and dyslipidemia. He had a history of non-STsegment elevation acute coronary syndrome two years earlier, during which he underwent coronary angioplasty on the right coronary artery. The patient was asymptomatic until six months prior to his consultation, when he started with angina type II and SPECT was performed, which showed moderate ischemia in circumflex territory. He was referred to the Interventional Cardiology Unit for percutaneous coronary intervention. Coronary angiography was performed by femoral access with Super Sheath introducer (Boston Scientific) 6 FR and diagnostic catheters 6 FR Judkins Left 3.5 and Judkins Right 3 Impulse (Boston Scientific) finding the right coronary artery without significant angiographic lesions and the birth of the left coronary artery trunk was observed from the same right coronary sinus. At this level the presence of a significant obstruction from the middle segment of the circumflex artery can be observed (Figures 1 and 2). In a programmed way (Figures 3 and 4) and by Femoral access with Super Sheath 6 FR introducer and Convey Left 6 Fr Guide Catheter (Boston Scientific) was performed through Choice Floppy guide wire $0.014 \times 180$ (Boston Scientific), which with difficulty due to severe tortuosity was positioned in the distal segment of the Circumflex artery, dilatation with Emerge 2. 5 x $15 \mathrm{~mm}$ Coronary Balloon. (Boston Scientific) and final implantation of a $3.0 \times 16 \mathrm{~mm}$ Promus Premier type Everolimus Coronary Stent (Boston Scientific). 


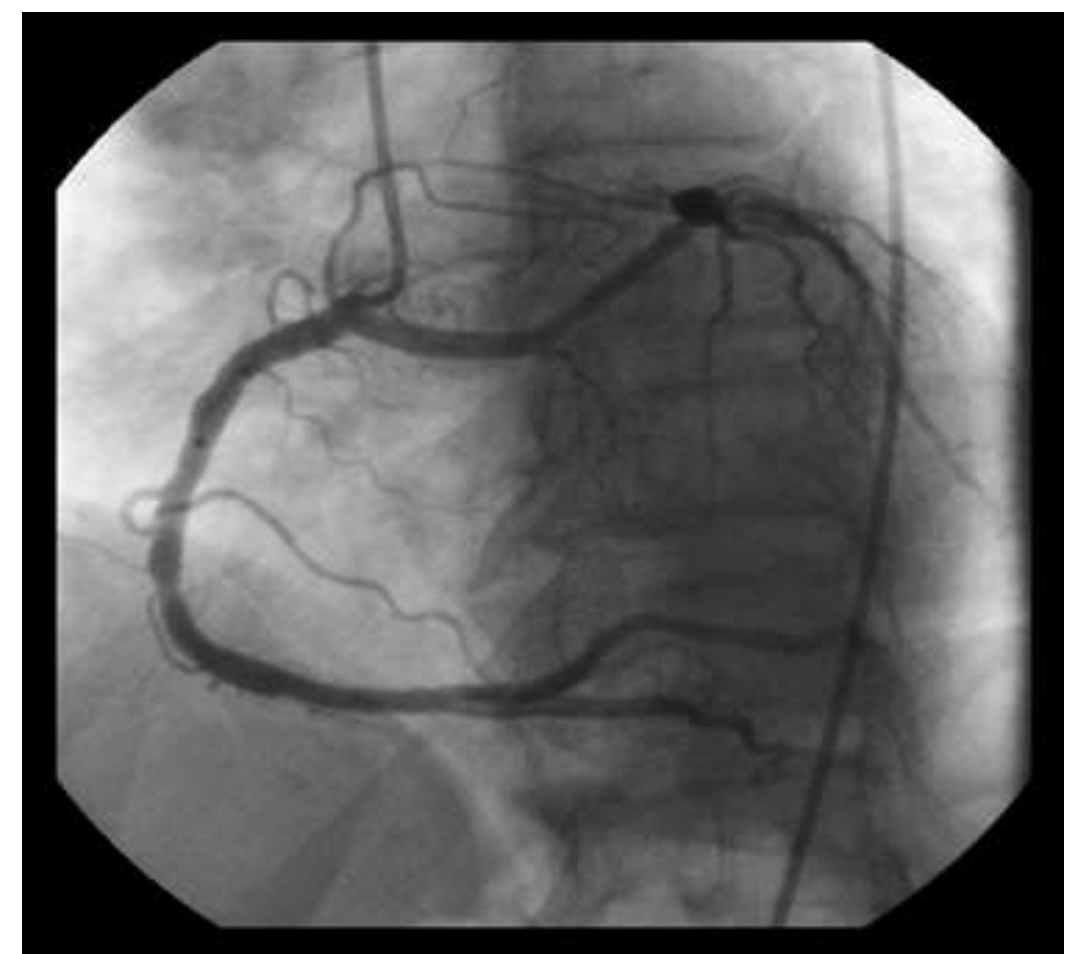

Figure 1: During angiography of the right coronary artery, the origin of the left coronary artery is observed in the same sinus.

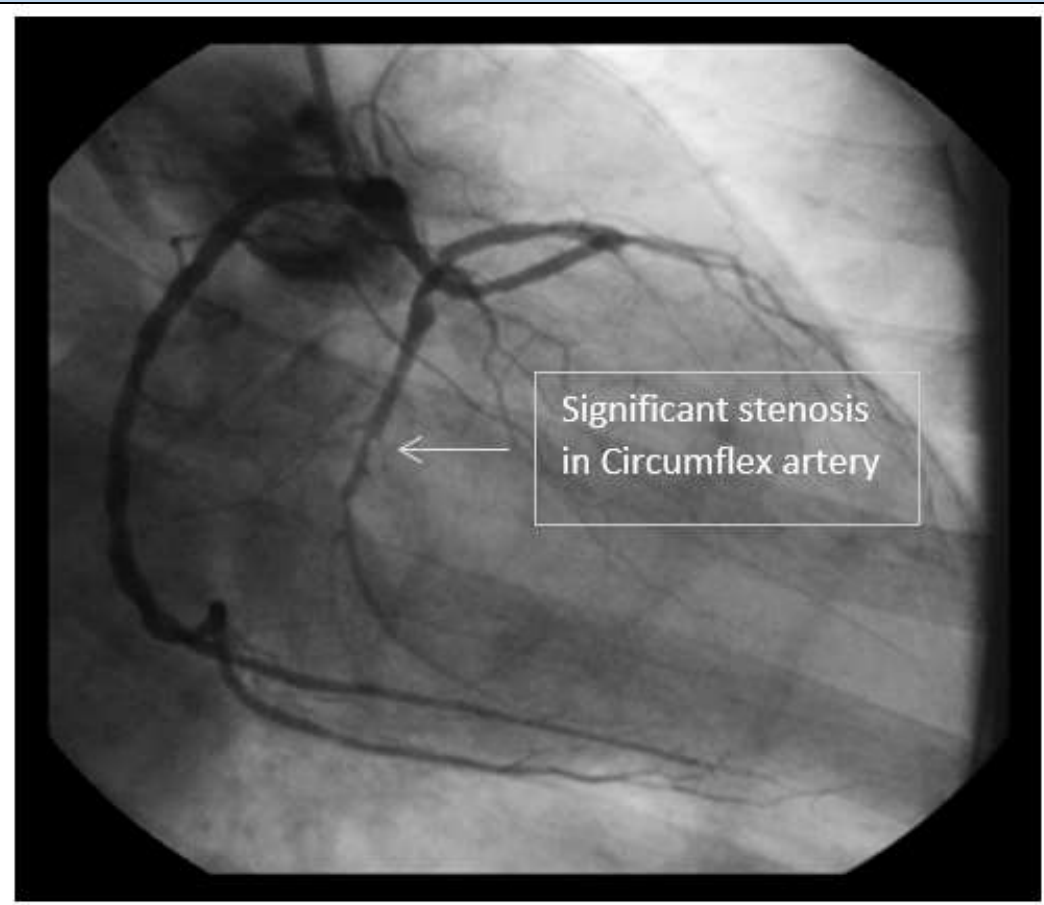

Figure 2: Identification of significant lesion at the distal segment of the anomalous circumflex artery. 


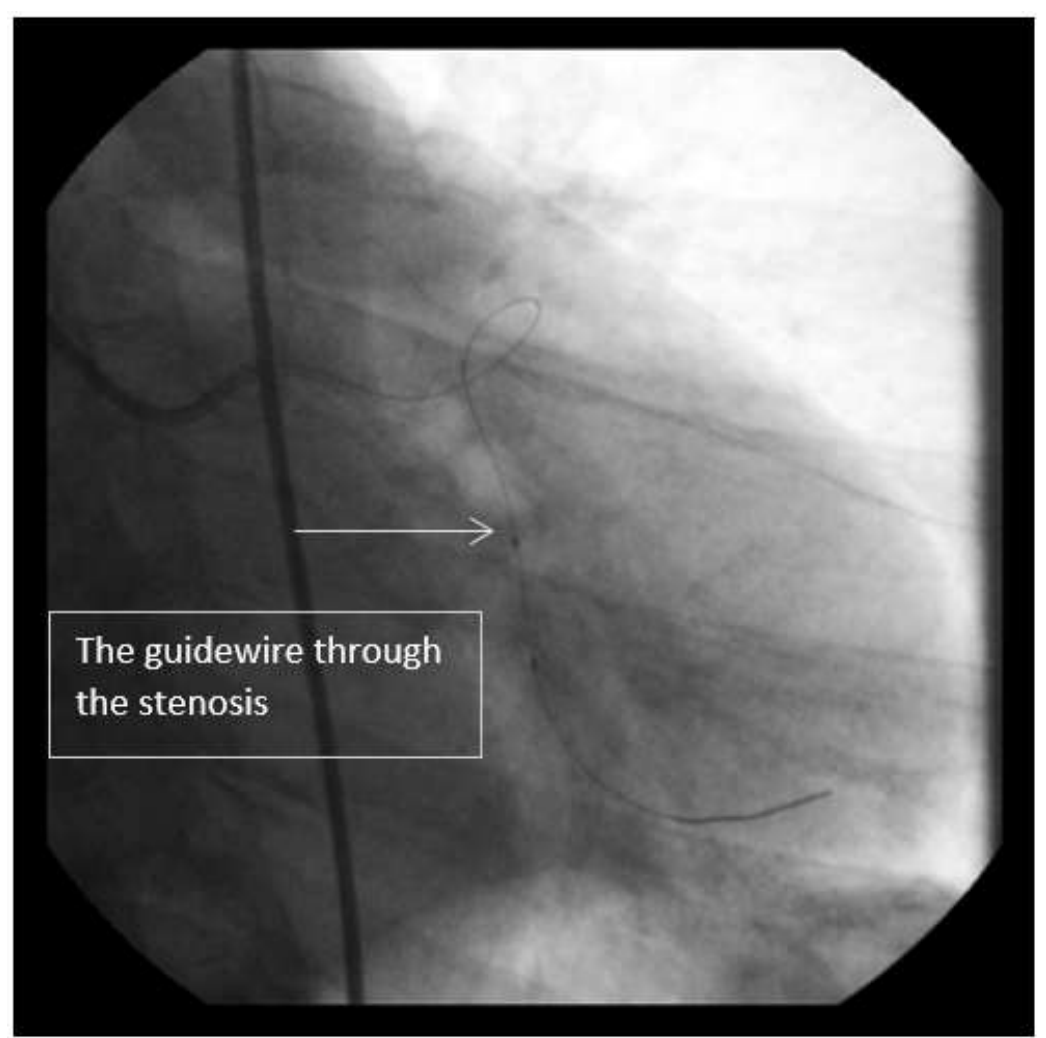

Figure 3: Lesion crossing with 0.014 Floppy 0.014 treatments with $2.5 \times 15$ mm coronary balloon and 3.0 x $16 \mathrm{~mm}$ Drug

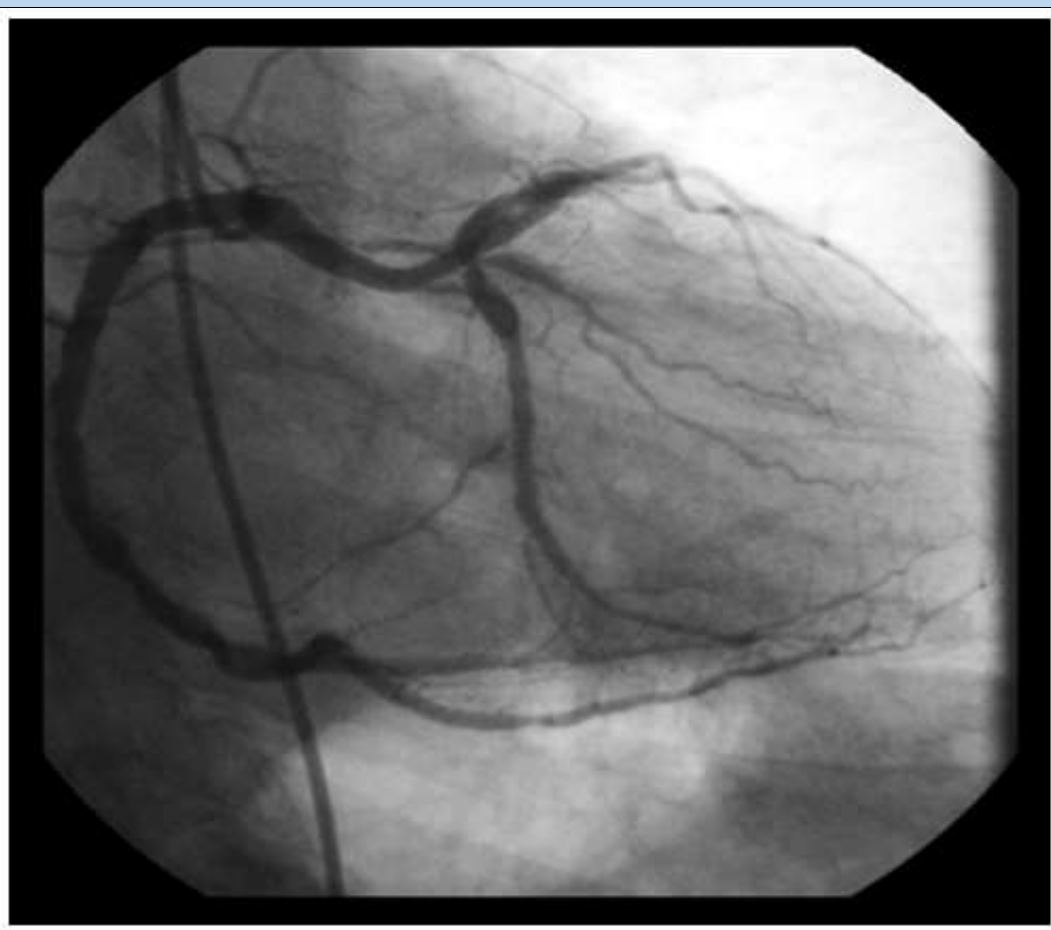

Figure 4: Final result, with resolution of the pre-existing lesion, with no residual lesion observed.

\section{Discussion}

Coronary artery anomalies identified by coronary angiography are unusual findings [1], among which the origin of the left coronary artery in the right sinus of Valsalva is a very rare pattern with an incidence between 0.2 and $1.2 \%$ according to the series [5].
Patients with this anomaly are usually clinically asymptomatic, with the exception that the anomalous trajectory runs between the aorta and the pulmonary artery, which can cause sudden death, especially during physical activity [2]. The incidence of severe symptoms is approximately $20 \%$ [7, 8]. The association between this anomaly and coronary 
atherosclerotic disease is not a common occurrence; however, when it does exist, it rarely affects the anomalous segment [3]. In the case of the presence of obstructive atherosclerotic plaque on the anomalous territory, it develops more aggressively and in earlier stages from the pathophysiological point of view [3].

Coronary angiography is the method of choice for the identification of atherosclerotic lesions [4], however, it can cause some diagnostic problems in the three-dimensional identification of the course of the anomalous artery. In this regard, multislice computed tomography (MSCT) helps to better visualize the proximal portion, size, course and relationship of the anomalous vessel with the surrounding structures [9]. Our case refers to a patient in the sixth decade of life in which a possibly benign anomalous trajectory is considered, with a proven history of atherosclerotic disease on the right coronary artery and with complementary studies that showed the presence of ischemia. Due to these conditions, it was decided to perform coronary angioplasty on the lesion found [6].

Conflict of Interests: Not declared

\section{References}

1. Angelini P, Velasco JA, Flamm S. Coronary anomalies: incidence, pathophysiology, and clinical relevance. Circulation 2002; 105: 2449-2454.

2. Chaitman BR, Lesperance J, Saltiel J, et al. Clinical, angiographic, and hemodynamic findings in patients with anomalous origin of the coronary arteries. Circulation 1976;53: 122-131.

3. Click RL, Holmes DR, Jr, Vlietstra RE, et al. Anomalous coronary arteries: location, degree of atherosclerosis and effect on survival: a report from the Coronary Artery Surgery Study.

J Am Coll Cardiol 1989; 13: 531-537.

4. Gersony WM. Management of anomalous coronary artery from the contralateral coronary sinus. J Am Coll Cardiol 2007; 50: 2083-2084

5. Ugalde H, Ramirez A, Ugalde D, Farias E, Silva AM. Anomalous birth of coronary arteries in 10,000 adult patients undergoing coronary angiography. Rev Med Chil 2010; 138: 7-14.

6. Grasso AE, Pennell DJ. Myocardial infarction related to aberrant left circumflex artery, Int J Cardiol 2010; 138: 51-52.

7. Bocal C, Sargin M, Iyem H, Akay, HT, Bingol H, Tatar H. Coronary artery anomalies: anomalous origin of the left coronary artery and circumflex branch in two patients. Exp Clin Cardiol 2006; 11:314-316

8. Silver MM. Suden cardiac death in infants and children. En: Fineschi V, Baroldi G, Silver MD. "Pathology of the Heart and sudden death in forensic medicine". $1^{a}$ ed. Ed. CRC. Boca Raton 2006. Cap. 7. pp 17.

9. Sarria S, Arteche E, Certo M, Fernandez G. Multidetector CT assessment of anatomical variants in coronary arteries. Colomb Med 2007; 38: 263-273.
This work is licensed under Creative Commons Attribution 4.0 License

\section{To Submit Your Article Click Here: Submit Manuscript}

DOI: $10.31579 / 2641-0419 / 207$

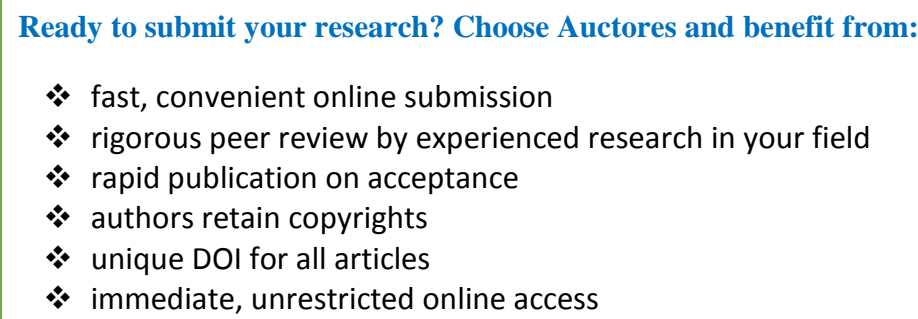

At Auctores, research is always in progress.

Learn more auctoresonline.org/journals/journal-of-surgical-case-reportsand-images 